\title{
Heat Stroke Manifesting as Cardiac Arrest and Multi-Organ Failure
}

\author{
Rajesh Rajan, Osamma Amin, Ayman Gaballa, Raja Dashti, Mohammed Al Jarallah \\ Department of Cardiology, Sabah Al Ahmad Cardiac Center, Al-Amiri Hospital, Kuwait.
}

\begin{abstract}
Corresponding Author:
Dr. Rajesh Rajan

Email: cardiology08@gmail.com

This is an Open Access article distributed under the terms of the Creative Commons Attribution License (creativecommons.org/ licenses/by/3.0).
\end{abstract}

Received : April 9,2017

Accepted : June 21, 2017

Published : July 25, 2017

\begin{abstract}
Background: Diseases and conditions related to myocardial infarction are frequent causes of emergency visits and lead to delayed diagnosis of other common conditions. Case Report: This is a case of a 23-year-old Bangladeshi young man who was working on an offshore oil rig based in Kuwaitas a manual labour. He had a cardiac arrest associated with malignant arrhythmias and ischemic cerebral infarction which was mostly contributed by an exertional heatstroke. The outside temperature during the event was nearly 45 degrees Celsius. He was initially treated with a provisional diagnosis of acute myocardial infarction. Patient developed multi-organ damage and recovered with intensive care. Ischemic cerebral infarction related symptoms improved steadily. Conclusion: This article point towards the importance of proper history taking and prompt diagnosis of heat stroke for the proper management during initial hours of presentation.
\end{abstract}

Keywords: Arrhythmias, Heat stroke, Myocardial Infarction, Renal Insufficiency, Rhabdomyolysis.

\section{Introduction}

Heat stroke was first described by Romans during the year BC 24 [1]. It is a fatal condition that occurs as a result of an elevated core body temperature to $104^{\circ} \mathrm{F}\left(40^{\circ} \mathrm{C}\right)$ or higher, secondary to prolonged exposure to a high environmental temperature [2]. It can cause central nervous system dysfunction, myocardial infarction, renal failure and muscular dysfunction [3]. It is classified into two types, exertional and non-exertional or classic [4]. It's a medical emergency with an estimated $10 \%-50 \%$ of mortality rate [1]. Reduction of body temperature is vital while resuscitating such patients [5].

\section{Case Report}

A 23-year-old light built Bangladeshi male working in a Kuwait based oil rig as manual labour with no significant past medical history presented to emergency room (ER) as a case of cardiac arrest with ventricular fibrillation. He was fasting whole day as it was the month of Ramadan. He was working outside where the temperature is nearly
45 degree Celsius. He was new to such extreme weather conditions as he reached Kuwait only eight months prior to the presentation. He had this event while emptying his bladder. He was febrile initially as per bystanders. Maximum recorded temperature peripherally was $38.5^{\circ} \mathrm{C}$. Rhythm strip taken at emergency room (ER) showed ventricular fibrillation. Initial troponin was $18.4 \mathrm{ng} / \mathrm{mL}$ with very high D-Dimer: 10,969 mg/mL, creatine kinase (CK): 14,675 IU/L and creatine kinase muscle brain fraction (CKMB): 537.4 IU/L. Hypokalemia and hypoglycemia were noted with mild renal impairment with creatinine $177 \mu \mathrm{mol} / \mathrm{L}$. Urine specific gravity was low (1.015). Arterial blood gas analysis $(\mathrm{ABG})$ showed metabolic acidosis. white blood cell (WBC): $20.4 \times 10^{9} / \mathrm{L}$, pro-calcitonin (PCT): $6.3 \mathrm{mg} / \mathrm{mL}, \mathrm{C}$-reactive protein (CRP): 95 $\mathrm{mg} / \mathrm{L}$ was noted high. Virology screen including $\mathrm{HBV}, \mathrm{HCV}$ and HIV were negative but high alanine aminotransferase (ALT): $229 \mathrm{IU} / \mathrm{L}$ and aspartate aminotransferase (AST): 460 IU/L. Bedside echocardiography showed global hypokinesia with ejection fraction $(E F)=25-30 \%$. He was intubated 
and taken to cathlab with a provisional diagnosis of acute coronary syndrome. Coronary angiogram showed normal coronaries. Computed tomography (CT) brain and CT pulmonary angiography done was normal. Electrocardiogram (ECG) taken post CAG showed diffuse ST elevation in anterolateral leads with ST depression in the inferior leads [Fig.1]. Electroencephalogram (EEG) done on day three showed abnormal study. MRI brain done showed acute non-isolated corpus callosal splenium infarction and subtle right pareto-occipital ischemic infarction. Cardiac MRI done at $3^{\text {rd }}$ week showed ejection faction $(E F)=38 \%$, large secundum atrial septal defect (ASD) with left to right shunt $\mathrm{Qp}: \mathrm{Qs}=2.51$, right atrium and right ventricle dilated. All the above clearly suggesting the patient had exertional heat stroke and associated complications.

\section{Discussion}

Multi-organ failure is common in heat stroke victims and it mainly causes damage on cardiovascular, neurological and renal system [6]. Most of the time pathophysiology mimics sepsis [7]. Diagnosis of heat stroke can be confirmed when the patient has hyperthermia with central nervous system involvement.

Body temperature should be measured rectally or directly from esophagus. It is not advisable to take the body temperature peripherally as it will be always less than one degree from the actual body temperature. Most of emergency room staff records the peripheral body temperature of the arrested heat stroke patients and the initial management of arrested patients usually involves the administration of plenty of intravenous (IV) fluids which contributes to the further drop in body temperature. Our patient was febrile before arrest as per the bystanders. In the ER initially the peripherally recorded temperature was normal. Later it started peaking for which patient received multiple ampoules of IV paracetamol during the hospital stay.

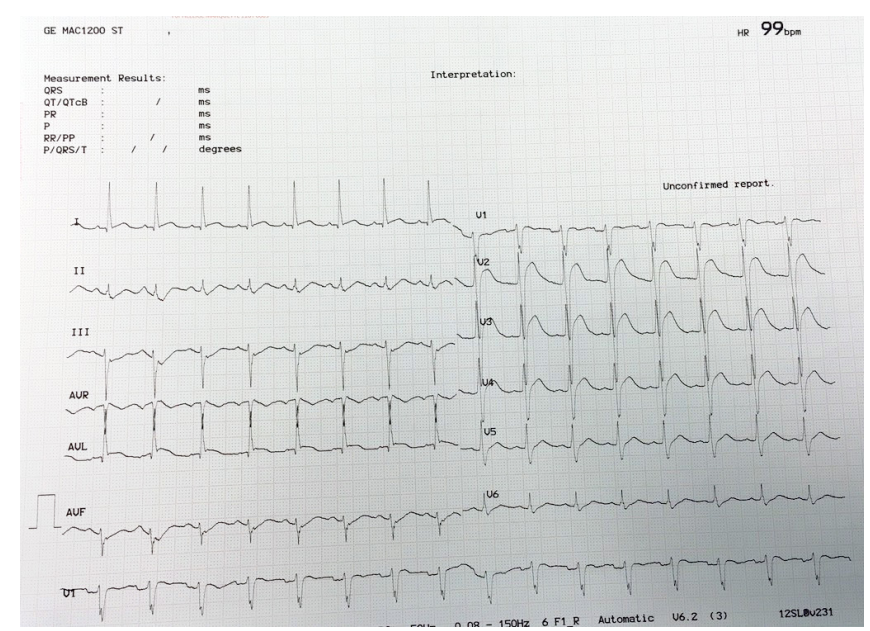

Fig.1: ECG showed diffuse ST elevation in anterolateral leads with ST depression in the inferior leads.

Heat stroke is known for causing cardiovascular related abnormalities like hypotension, electrolyte imbalance, ECG changes suggestive of malignant arrhythmias, ischemia, intra-ventricular conduction defects, QT prolongation, right bundle branch block and echocardiographic evidence of depressed cardiac function with global hypokinesia $[3,4]$. Our patient presented to emergency room as case of cardiac arrest with ventricular fibrillation. Coronary angiogram (CAG) failed to show any abnormality like other reported cases of heat stroke. ECG taken post-CAG showed diffuse ST elevation in anterolateral leads with ST depression in the inferior leads. He had left ventricle systolic dysfunction, $\mathrm{EF}=25-30 \%$ which improved and became near normal to $50-55 \%$ over a period of 4 weeks.

Heat stroke is known for causing neurologic abnormalities like encephalopathy, cerebral ischemia, and cerebral edema $[2,8]$. Our patient had ischemic cerebral infarction and the associated symptoms improved steadily. Heat stroke is known for causing following renal, muscular and gastro related complication [9]. Our patient had mild renal failure, rhabdomyolysis and mildly elevated liver enzymes. He also had hypoglycemia, electrolyte imbalance (hypokalemia) and metabolic acidosis. 
Treatment involves stabilizing the patient, airway maintenance, arterial blood gas analysis. Management check list should include ABG analysis, intravenous access with proper fluid management, and esophageal or rectal temperature monitoring. Avoid iatrogenic hypothermia. Foleys to be inserted to monitor and maintain urine output of $3 \mathrm{~mL} / \mathrm{kg} / \mathrm{h}$ to minimize the risk of renal failure. In addition, consider oxygen therapy, urine output and electroencephalographic monitoring, and surgical consultation if suspicion of compartment syndrome. Aggressive reduction of body temperature during the golden hour is vital to avoid multi-organ failure The goal of treatment is to reduce the temperature by at least $0.2^{\circ} \mathrm{C} / \mathrm{min}$ to approximately $39^{\circ} \mathrm{C}$. Active external cooling generally is halted at $39^{\circ} \mathrm{C}$ to prevent iatrogenic hypothermia. Pharmacologic measures include the calcium for patients with arrhythmias and hyperkalaemia; hypertonic dextrose and sodium bicarbonate IV fluids to treat electrolyte imbalance and rhabdomyolysis. Barbiturates, benzodiazepines, dantrolene, and mannitol are recommended for symptom based management.

\section{Conclusion}

Heat stroke is a condition which may mimic myocardial infarction or cerebrovascular accident in the initial presentation. Proper history taking and timely diagnosis can help to decrease mortality.
Contributors: RR: manuscript writing, literature search and case management; OA, AG, RD, MAJ: manuscript editing, literature search and case management. RR will act as guarantor. All authors approved the final version of the manuscript.

Funding: None; Competing interests: None stated.

\section{References}

1. Bouchama A. Heatstroke: a new look at an ancient disease. Intensive Care Med. 1995;21:623-625.

2. Bouchama A, Knochel JP. Heat Stroke. N Engl J Med. 2002;346:1978-1988.

3. Knochel JP. Exertional heat stroke-pathophysiology of heat stroke. In: Hopkins PM, Ellis FR, eds. Hyperthermic and Hypermetabolic Disorders. Cambridge: Cambridge University Press, 1996;42-62.

4. Shahid MS, Hatle L, Mansour H, Mimish L. Echocardiographic and Doppler study of patients with heat stroke and heat exhaustion. Int J Cardiac Imaging. 1999; 15:279-285.

5. Guidelines - American College of Sports Medicine Joint Statement. National Athletic Trainers' Association. Inter-association task force on exertionalheat illnesses consensus statement. 2003.

6. Alzeer AH, Al-Arifi A, Warsy AS, Ansari Z, Zhang $\mathrm{H}$, Vincent JL. Nitric oxide production is enhanced in patients with heat stroke. Intensive Care Med. 1999;25:58-62.

7. Duthie DJR. Heat-related illness. Lancet. 1998;352:13291330 .

8. Glazer JL. Management of heatstroke and heat exhaustion. Am Fam Physician. 2005;71:2133-2140.

9. Hsu YD, Lee WH, Chang MK, Shieh SD, Tsao WL. Blood lactate threshold and type II fibre predominance in patients with exertional heatstroke. J Neurol Neurosurg Psychiatry. 1997;62:182-187. 